\title{
Maldito bem dito, Bendito mal dito: construções discursivas a partir da trajetória de Itamar Assumpção ${ }^{1}$
}

\section{Cursed or Blessed: discursive constructions of Itamar Assumpção's trajectory}

\author{
Larissa Caldeira², Jorge Cardoso Filho ${ }^{3}$
}

1 Uma versão inicial deste artigo foi apresentada na disciplina "Temas em teorias da análise de produtos e linguagens da cultura mediática" (UFBA), ministrada pelas professoras doutoras Itania Gomes e Juliana Gutmann, a quem agradecemos pelos comentários e sugesões. Cultura contemporânea no PósCom UFBA. E-mail: larissa.cgp@gmail.com. 


\section{Resumo}

Este artigo analisa as disputas valorativas estabelecidas nas críticas culturais brasileiras acerca da noção de "maldito", tendo como ponto de partida a carreira musical de Itamar Assumpção, levando em conta os processos de contextualização radical (GROSSBERG, 2010) e as formações discursivas (FOUCAULT, 1987) da crítica cultural. Considerando as nuances e as complexidades do sentido do termo "maldito" a partir das experiências e expectativas, conforme Koselleck (2006), como uma tentativa de demonstrar a emergência de valores e valorações, discursos e sensibilidades, e relações de poder diante dos regimes de verdade, é possível notar como as articulações estético-políticas do termo se reorganizam em função de temporalidades e historicidades.

\section{Palavras-chave}

Maldito, crítica, formações discursivas, disputas, contextualização radical.

\section{Abstract}

This article analyzes the value disputes established in Brazilian cultural criticisms about the notion of "cursed", taking Itamar Assumpção's musical career as a starting point, taking into account the processes of radical contextualization (GROSSBERG, 2010) and the formations discursive (FOUCAULT, 1987) of cultural criticism. Considering the nuances and complexities of the term "cursed", based on experiences and expectations, according to Koselleck (2006), as an attempt to demonstrate the emergence of values and valuations, discourses and sensitivities, and power relations in the face of regimes of truth. In fact, it is possible to notice how the aesthetic-political articulations of the term are reorganized according to temporalities and historicities.

\section{Keywords}

Cursed, criticism, discursive formations, disputes, radical contextualization. 


\section{Introdução}

O artigo pretende observar as disputas em torno da caracterização de "maldito" na música brasileira, a partir da trajetória do cantor e compositor paulista Itamar Assumpção (1949-2003), considerando as nuances desse termo na carreira musical do artista e como ele é disputado em formações discursivas (FOUCAULT, 1987) da crítica cultural. Nesse sentido, partimos da ideia de que o rótulo de "maldito" pode ser também entendido enquanto "uma imagem conceitual que deixa ver diferentes problemas temporais nos fenômenos midiáticos e que pode sugerir alguns caminhos para sua apreensão". (RIBEIRO; LEAL; GOMES, 2017. p. 46).

Nosso ponto de partida são as ambiguidades discursivas acerca da noção de maldito, por vezes atribuída ao músico pela crítica, e que é recorrentemente disputada pelos críticos e artistas. Desde o século XIX, o termo "maldito" ou a alcunha de "artista maldito", no campo da cultura popular (que inclui desde a música, o teatro, as artes plásticas e a poesia) demonstra uma série de performances verbais e construções de discursos distintos entre si. Os poetas franceses considerados malditos, como Arthur Rimbaud, Charles Baudelaire, Paul Verlaine, Stéphan Mallarmé, Tristán Corbière, Jules Laforgue e Charles Cros (VIVAS, 2015), são um exemplo disso, à medida que, segundo consta, ao promover um tipo de vanguarda, instabilizou e desestabilizou, de certa forma, a crítica e a sociedade de seu tempo com um tipo de sensibilidade e expressão poética não localizada em um ordenamento estético prévio, ou em um pressuposto de valores e valorações que contemplavam aquele espaço-temporal.

No caso da música brasileira, principalmente, entre os anos 1970 e 1980, a referência ao maldito esteve ora associada à dificuldade de venda e caráter pouco comercial de algumas produções, e/ou a um selo de qualidade e distinção ${ }^{4}$ dentro daquilo que se entende como música popular brasileira (MPB). Neste rol de artistas que foram considerados malditos, podemos citar Jards Macalé, Luiz Melodia, Sérgio Sampaio, Jorge Mautner, Belchior, Tom Zé, Ângela RoRo, Walter 
Franco, Itamar Assumpção e outros. Contudo, não somente na música se pode observar disputas valorativas e formações discursivas acerca do maldito - no teatro, nomes como os de Plínio Marcos e Zé Celso Martinez, e, na poesia e literatura, de Ana Cristina César, João Antônio, Paulo Leminski, Augusto dos Anjos, Eduardo Guimarães, Álvares de Azevedo, e mais recentemente, de Rubem Fonseca e Alice Ruiz 5 . Todos artistas, músicos, poetas, poetisas, cantores e cantoras que em temporalidades específicas foram colocados como malditos, marginais ou de vanguarda perante as atribuições da crítica.

Uma reflexão mais aprofundada sobre o tema pode nos revelar, analiticamente, que em termos de formações discursivas, falar sobre as disputas em torno de como se nomeiam esses poetas também demonstra oscilações na ordem dos discursos. Tendo em conta, por exemplo, que muitos deles não foram, necessariamente, considerados malditos, mas "poetas marginais". O que, de alguma forma, parece ir ao encontro com formações discursivas anteriores, que consideravam os poetas franceses como os "grandes malditos do séc. XIX", poetas esses que são citados no texto da Folha de São Paulo ("ARTISTAS...", 2013) para defender certa impossibilidade de ser maldito hoje. Entretanto, partindo de uma relação de construção de contextos e grau de historicidade do próprio maldito, intentamos dizer que não há, impreterivelmente, uma impossibilidade de ser marginal, nem de ser afastado da sociedade, nem de ser vanguardista, ou mesmo "artista maldito". Em nossa percepção, os sentidos e as identificações sobre o que é ser maldito sofre mudanças de ordens espaçotemporais, e isso pode ter a ver com as dinâmicas culturais, sociais, estéticas e políticas, que se diferenciam de uma sociedade a outra, como reflexos das mudanças do tempo. Levando em conta que o próprio modo de ser maldito, ou o significado do que é ser "artista maldito", "poeta marginal", "artista de vanguarda" não possuem fixidez ou determinações prévias quando se considera tais dinâmicas. 
Nessa perspectiva, a partir de Grossberg (2015), compreendemos que as relações são tanto contingentes (construídas) quanto reais (eficazes), um espaço de articulação e contextualização anti-esssencialista, que leva em consideração as formas, modalidades, mecanismos e práticas de relacionalidade, o que envolve as práticas musicais e estético-políticas de Itamar, as atribuições e formações discursivas da crítica, as lógicas de produção e recepção, e os formatos da indústria fonográfica brasileira. Ressaltamos que, embora se considere essas lógicas e formatos, nosso foco se encontra nos discursos sobre os malditos. Assim, temos o compromisso com a contextualização radical (GROSSBERG, 2010), que propõe investigar os contextos, e não os objetos, para neles adentrar enquanto construções sempre abertas, mutáveis e porosas, estratégicas e temporárias (GROSSBERG, 2015).

\section{O maldito como historicidade e temporalidade}

Dessa maneira, se tem a compreensão de que a lógica do mercado musical e da crítica cultural contemplam certas nuances e misturas consideradas aceitáveis para o censor estético ${ }^{6}$ em vigor, ou melhor, diante das institucionalidades e ambiguidades na música do Brasil. Se artistas como Itamar Assumpção são, por vezes, considerados difíceis, isso pode ter a ver não somente com as experimentações sonoras que soam complicadas para serem classificadas ou consumidas no mercado. As relações entre as temporalidades e historicidades do próprio termo maldito, as disputas e ambiguidades podem nos revelar processos que articulam e desarticulam as construções discursivas dos críticos, e que podem vir a demonstrar potenciais de estabilização e desestabilização da própria crítica cultural.

Por isso, é possível perceber que a relação de enfrentamento ou de apaziguamento, os processos de continuidades e descontinuidades da crítica e das próprias gravadoras (majors) com as expressões artísticas "não-consensuais", na relação com os espaços hegemônicos da música popular no Brasil (relacionados 
à $\mathrm{MPB}^{7}$, ao universo da canção, às grandes gravadoras e produtoras musicais e à relação de valor que alguns artistas possuem), podem denotar tanto disputas valorativas quanto performances verbais (FOUCAULT, 1987). Estas se dão através do maldito em articulação com as atribuições da crítica em veículos jornalísticos (jornais, revistas e sites brasileiros), como também pode revelar processos contínuos e descontínuos de forte configuração estético-política, à medida que envolve regimes de verdade e relações de poder (FOUCAULT, 2014).

Por outro lado, também se observa que a própria dificuldade de venda ou de identificação desses artistas no contexto popular pode ser classificada como um aspecto distinto deles na música brasileira, pois, eventualmente, o caráter experimental é exposto como um critério de qualidade, tanto nas construções discursivas em torno do maldito como nas disputas valorativas entre críticos e artistas.

Em distintas temporalidades, o maldito (mauditis - do francês "reprovado") foi comumente associado ao sentido de negação, renegação e rechaçamento. Quer seja na música, na poesia, na pintura, na literatura, no teatro ou no cinema, compreendemos que desde a popularização do termo (entre 1884 e 1888) por Paul Verlaine ${ }^{8}$ se pode observar os graus de historicidade (HARTOG, 2019) e as estruturas de formação de contextos acerca do maldito diante de um emaranhado discursivo.

Consideramos, inicialmente, que existe uma aparente sincronia das formações discursivas em torno do maldito, na relação com a crítica cultural, que deixam ver regularidades discursivas e construções em volta de seu aspecto distintivo ou caráter de qualidade dentro da música brasileira, todavia, estamos cientes de que tais enunciados discursivos estão dispersos no tempo, de que há uma suspensão das sequências temporais (FOUCAULT, 2008), que deixam ver relações que legitimações, aos artefatos midiáticos, aparatos tecnológicos de gravação, veiculação e inovações eletrônicas que reconfiguram, desde o século $\mathrm{XX}$, o parâmetro de música popular. 
caracterizam as diversas temporalidades dessas formações e articulam em série diante de um entrecruzamento, ou mesmo de uma ramificação arqueológica que envolve as regras de formação como um esquema não puramente simultâneo e linear dos discursos. Por isso, no nosso entendimento, tais construções discursivas em torno do maldito não decorrem de processos temporais sincrônicos, mas podem colocar entre parênteses o conjunto do processo diacrônico do tempo e no tempo, propondo que existam vetores temporais que contribuem para sua derivação e sucessão (FOUCAULT, 2008).

Em vista disso, se propõe uma abordagem que possibilite um tipo de descrição arqueológica dos discursos em torno do maldito, considerando os desdobramentos históricos e a trajetória artística de Itamar Assumpção em articulação com os formatos do mercado da música no Brasil, as relações sociais de poder, as disputas valorativas e os processos de estabilização e desestabilização da crítica cultural. Tal abordagem é concebida como forma de contextualizar radicalmente e compor contextos através dos pontos de articulação entre as formações discursivas e outras práticas não discursivas, levando em consideração que tais discursos sobre o maldito são práticas que têm suas formas específicas de encadeamento e de sucessão. Tomamo-lo como uma figura de historicidade possível, que pode deixar ver tanto reiterações quanto rupturas e tensionamentos com a crítica, tendo em conta as transformações no tempo e contextos não essencialistas.

Os contextos se constituem tanto em termos de seus limites quanto da pertinência de vários elementos e linhas de determinação possíveis. Em concordância com Grossberg (2010), pensamos em uma relação temporal não-linear, que dê conta de suas mudanças, apropriações, reapropriações, estabilização e desestabilização enquanto processos complexos. Isso nos convida a tomar os contextos como formas de identificar as nuances que se dão pela articulação das construções discursivas do maldito na crítica, como uma maneira específica e particular de construir tais contextos na música brasileira, através dos processos de articulação, rearticulação e desarticulação da utilização do termo maldito para se referir a Itamar Assumpção. 
Grossberg (2015, p. 15) afirma que a articulação define perguntas - quais são "as formas, modalidades, mecanismos e práticas de relacionalidade -, e não soluções propriamente ditas, por isso é uma prática de contextualização radical, o que aqui se investiga não são objetos, mas as maneiras de se adentrar em contextos". Consequentemente, acreditamos que é preciso analisar os modos de disputa, valores, valorações e sensibilidades articuladas ao termo maldito em formações discursivas da crítica na relação com a trajetória de Itamar. Assim, defendemos que nossa questão não está na essência, mas nas maneiras como as várias contradições são articuladas e vividas em relações de poder específicas. Nossa análise acontece nas disputas de poder, para articular e rearticular, mostrar e demonstrar que outras relações são possíveis com o maldito diante da trajetória de Itamar.

Com base em Grossberg (1997), entendemos que não basta identificar e analisar os textos e os discursos dos críticos, é preciso ir além e analisar as práticas discursivas, que, de maneira transversal aos contextos, nos ajudam a identificar as identidades e efeitos em qualquer prática cultural ou meio de comunicação. Isto posto, nos atentamos também às dimensões estética e política que emergem dessa articulação na música e entendemos que elas estão interligadas aos discursos, com base em espaços de experiências e horizontes de expectativas ${ }^{9}$ relacionados à carreira de Itamar Assumpção, "as especificidades das dinâmicas culturais, estéticas e políticas, que organizam e expressam valores que podem ser mapeados e analisados em expressões cotidianas" (CALDEIRA; FARIAS, 2019, p. 2). Nessa acepção, os textos dos críticos se tornam "locus de observação possível para compreender tais especificidades e dinâmicas", pois compreendemos que o espaço de experiências ajuda a perceber as relações discursivas estabelecidas com a trajetória de Itamar e "que foram projetadas no tempo presente, no qual aglomeram experiências, sensibilidades, expectativas e valorações, e que também uma outra maneira de ligação entre "futuro" e "passado". Assim, o horizonte de expectativas é constituído por formas de sensibilidade com relação ao "futuro" que se aproxima, mas também por aquilo que atualmente, num determinado presente, se realiza como experiências. 
deixam ver percursos valorativos, regularidades e descontinuidades discursivas" (CALDEIRA; FARIAS, 2019, p. 8).

\section{O maldito Itamar Assumpção: trajetória, disputas valorativas e crítica}

Acreditamos que as disputas valorativas e ambiguidades discursivas, as relações entre as temporalidades e historicidades do próprio termo maldito, em articulação com a trajetória do cantor e compositor paulista, podem revelar processos que articulam e desarticulam tais construções dos críticos, o que deixa ver os potenciais de estabilização, instabilização e desestabilização nos discursos. Tomamos como lócus de observação os espaços hegemônicos dos críticos brasileiros na ocasião, exercidos profissionalmente em colunas de jornais e revistas - uma limitação na elaboração de uma arqueologia discursiva da crítica, de forma mais ampla. No entanto, Stroud (2010) nos explica que mesmo com a aclamação crítica extremamente positiva, Assumpção não alcançou sucesso comercial nem ampla exposição popular.

Ao tomarmos o termo maldito como figura de historicidade, ampliamos o escopo de uma análise de contexto, indo além de uma visão restritiva ou relacionada a um único modo de ser maldito. Ainda que partamos da trajetória de Itamar, ressaltamos que nossa abordagem envolve complexidades, historicidades e temporalidades distintas - são práticas temporárias, provisórias e estratégicas, que sempre devem estar abertas a mais experiências e multiplicações.

Dessa forma, se o maldito é uma figura de historicidade possível, podemos notar através dos processos de articulação, desarticulação e rearticulação, com sua densidade histórica e espaçotemporalidade, que os valores e valorações chamados em causa nas construções discursivas da crítica cultural, para designar quem são ou quem não são os artistas malditos, seja na música brasileira ou em outros contextos da cultura, possibilitam ver oscilações e ambiguidades discursivas a serem consideradas. Assim, levamos em conta que a crítica pode ser pensada, em alguns momentos, enquanto um censor estético que se relaciona aos regimes de verdade, às disputas valorativas e às relações de poder, cuja intenção é manter uma ordem ou ordenamento de caráter hegemônico na cultura. 
Pode-se, então, afirmar que tais valorações sobre produções "nãoconsensuais" com esses regimes ou formas de ordenamento, como as produções de Itamar Assumpção, refletem uma tentativa também da crítica de estabilizar ou instabilizar determinadas práticas artísticas que, em alguma medida, desafiam suas institucionalidades e aspectos censórios. Todavia, como estamos aqui figurando uma contextualização radical, não tomamos os fenômenos como eventos fixos, universais e findados, senão como transitórios, mutáveis, imbricados e emaranhados. Portanto, notamos que quando se mapeia as construções dos críticos sobre o maldito ou sobre os artistas considerados malditos, é possível perceber os pontos de articulação nos quais o próprio maldito estabiliza, instabiliza e destabiliza as construções discursivas.

A publicação datada de 22 de maio de 2013, do Caderno Ilustrada da Folha de S. Paulo, parece reivindicar um aspecto autêntico e singularizante do maldito a ponto de negar sua existência no contexto contemporâneo. O título "Artistas malditos não existem mais", diz curador de colóquio da USP sobre o tema parece demonstrar como, em alguma medida, a crítica atua enquanto lugar de regulação, quando o termo antes tomado como negação e renegação ou como valor distintivo de qualidade é aqui entendido como um conceito que "[...] virou 'um mito que continua ativo para dar a dimensão sagrada ao artista num mundo onde não há mais o aspecto sagrado da arte $[\ldots]$ ", ou que "[...] a noção de (poeta) maldito diz respeito a uma relação com a sociedade, e a do século 19 era muito estreita" e que existiria uma "[...] impossibilidade dos malditos hoje" ("ARTISTAS...", 2013). Nessa construção discursiva, parece evidente que quando se aceita a priori o termo maldito, de alguma forma, se estabiliza própria a crítica.

Dessa forma, compreendemos que os espaços de experiência e os horizontes de expectativas (KOSELLECK, 2006) tornam possíveis perceber como os discursos da Folha ("ARTISTAS...", 2013) são marcados pelas temporalidades da experiência com aquilo que é considerado maldito, a partir de uma forte relação entre passado e futuro, o que pode compor uma dialética que sintetizaria no tempo presente as experiências e expectativas dos interlocutores. A dissipação de possibilidades e 
sensibilidades se dá mediante horizontes de expectativas, enquanto um aglomerado que forma um todo em muitos substratos de tempos anteriores. Pois notamos nessa construção discursiva certa cristalização nostálgica de um tempo que "era bom", e ele "era bom" naquela sociedade do século XIX na qual, supostamente, existiam malditos "de verdade", o que remete a expectativas e experiências diante de uma ou mais questões históricas entre um passado que se foi, um presente que não é e um futuro impossível de existir.

Ressaltamos também que o texto da Folha ("ARTISTAS...", 2013) revela uma problemática para os Estudos Culturais, principalmente no que tange às noções de "arte sagrada", "aura" versus o popular, cultura versus sociedade. Se compreendermos a cultura como um modo integral de vida, conforme Williams (1979), estamos partindo não de um estudo da cultura como "arte sagrada" e "aura", mas nos guiamos por uma investigação que busca entender o porquê de tais expressões culturais serem mais valorizadas que outras. Destacamos que Grossberg (1997) recusa a noção de popular como parte da historiografia tradicional, ortodoxa e moderna que intenta relacioná-lo a dois modos analíticos e restritivos, baseados na cultura popular versus legitimação ou no popular versus mainstream ${ }^{10}$. Para o autor, se faz necessário considerar o duplo movimento de "controle" e resistência do popular e levar em consideração as tensões, disputas entre o dominante e a cultura legitimada. Fazendo isso, tomamos o espaçoproblema em articulação com as distintas temporalidades e os diferentes contextos, para se compreender a relação de forças e lutas que operam em torno desses processos, pois a relação entre o popular e a cultura legitimada é uma relação de luta política e as construções dos discursos são vistos como lutas de poder.

Podemos dizer que, de algum modo, afirmações como "artistas malditos não existem mais" ("ARTISTAS...", 2013) revelam não apenas ambiguidades discursivas da crítica e processos de disputas valorativas acerca do maldito, como também certa "incapacidade", muito comum, de reconhecer as mudanças na operação 
da cultura e do popular para além de formas descontextualizadas, binárias e essencializadas. É preciso pensar nas complexidades das práticas culturais e tensionar a própria noção de cultura ${ }^{11}$, em articulação com as dimensões dos discursos, dos aparatos técnicos e tecnológicos, dos aspectos socioeconômicos e políticos, das relações de disputas e de poder em torno do maldito, que convocam valores e valorações distintos diante de sua historicidade.

A partir disso, podemos observar que não existe um padrão ou uma padronização para o maldito, tendo em conta que tal alcunha atravessa diversos artistas em diferentes áreas da cultura diante de distintas espaçotemporalidades. Entretanto, existem proximidades e aproximações possíveis entre eles, principalmente daquilo que diante do popular e do moderno se considera como vanguarda e experimentalismo, como anticomercial ou independente, como alternativo em relação ao hegemônico.

Em Benedito João dos Santos Silva Beleléu, Vulgo Nego dito, maldito bendito, Itamar, publicada no site Çaravá Culture no dia 2 de setembro de 2015, podese observar uma construção discursiva em torno do alternativo e da vanguarda paulista: "[...] Itamar foi sem dúvida um dos nomes mais importantes da cena alternativa. Também fora chamado de maldito por se rebelar e encabeçar um movimento contra o controle das gravadoras. [...]" (KALIK, 2013). Neste ponto, se pode perceber que o censor estético da crítica se articula e desarticula com as demandas do mercado da música, boa parte dele gerido e controlado pelas grandes gravadoras ou majors. Todavia, notamos que as oscilações dos discursos dos críticos não apenas se associam aos processos de produção e recepção, mas tem relação com as experiências e expectativas, com os modos de organização e distribuição de sensibilidades e do sensível que atravessam tais formações discursivas acerca do maldito na trajetória do músico paulista.

Diante disso, ressaltamos que as complexidades dos discursos e as disputas valorativas quanto à cena alternativa e à acepção de artista maldito

11 Cultura tomada enquanto aura artística, sendo apartada das relações socioeconômicas e políticas, estando apartada da sociedade, colocado num "pedestal" e distanciamento da vida humana. 
perpassam a carreira de Itamar Assumpção, desde as atribuições e oscilações da crítica às suas declarações em entrevistas que circularam na época até em suas composições musicais. De certa forma, o artista parece reivindicar o "seu" espaço distintivo na música brasileira numa relação com o alternativo, ao declarar, por exemplo, que "eu não tenho preço, bem mal te conheço, não estou à venda, menina", na música Código de acesso (1998), ou ao se autointitular como "vulgo Nego Dito, Nego Dito cascavé" "pra provar, pra quem quiser ver e comprovar", na composição Nego Dito (1980). Demonstra assim o que parece ser um modo de disputar com os discursos que Ihe atribuíam a alcunha de maldito, quando se autoproclama "não-vendido" ao mercado de discos ou como "nego dito" que não "abaixava a cabeça" ou que "não fazia concessões mercadológicas", conforme se pode observar na entrevista concedida a Antônio Abujamra, no programa Provocações (2001), da TV Cultura:

[...] eu não quero fazer música para mercado [...] pois não é possível [...] eu saquei que um criolo metido a compositor no Brasil, teria que entender aquele Arrigo Barnabé [...] aquela música que é atonal [...] ah! Arrigo é chato, chato é você [...] você quer transferir sua chatice de não saber nada? [...] acomodou-se com esse ouvidinho de mercado! O que eu tenho a ver com isso? [...]. (ASSUMPÇÃO, 2001)

Isso pode ser também observado em declarações e entrevistas de Itamar, quando perguntado: "esse maldito quer dizer o que?", costumava responder: "livre!" ou "eu estou seguindo um caminho livre de qualquer tipo de imposição", conforme se pode ver no documentário Daquele instante em diante $(2013)^{12}$, de Rogério Velloso. Essas disputas do próprio Itamar com as construções discursivas do maldito e sua afirmação de "artista livre e único" diante de uma forte relação com o ser "artista independente" ou "alternativo" às majors, aparacem novamente na entrevista ao programa Provocações (2001), no qual o músico paulista declarou: 
Esse maldito aí, é o livre, estou falando sobre isso faz tempo, Itamar Assumpção, artista brasileiro, o único livre, me cita outro?! Livre que estou dizendo é o seguinte: eu não posso fazer só o meu sambinha [...] eu tenho que chegar tocando contrabaixo, fazendo arranjo, compondo, montando banda e monte de coisa que tem ligação com todas as artes, cinema, teatro, com tudo. [...]. (ASSUMPÇÃO, 2001)

Por conseguinte, podemos dizer que existe uma relação forte do artista disputando o maldito com as formações discursivas dos críticos diante de regularidades e desregularidades dos discursos em torno do termo, que evoca relações de poder acerca da música brasileira, das cenas musicais, das questões étnico-raciais num país desigual, dos aspectos estéticos, políticos e sociais no Brasil. Isso nos ajuda a perceber como, a partir da trajetória de Itamar, é também possível colocar o termo maldito numa relação de crise em articulação com as construções dos discursos a sua volta, o que deixa ver as continuidades e descontinuidades desses processos.

Em Nego Dito Cascavé já não é mal-dito, publicada na coluna Folha de Hoje, em 20 de dezembro de 1989, no jornal Folha de S.Paulo, as experiências e as expectativas parecem se aglomerar e compor um substrato espaço-temporal que reivindica de Itamar Assumpção sua identidade alternativa, seu universalismo experimental e sua veia artística independente, como o artista maldito que não se rende ou que não se vende aos ditames das majors ou aos ordenamentos estéticos e censores da crítica. O texto atesta as produções consideradas independentes, o LP Beleléu, Leléu e Eu (1980) e o disco ao vivo Às próprias custas (1981), ressaltando sua veiculação e circulação "[...] pelo boca-a-boca e pela Ipanema FM, que naquela época podia-se dizer que era alternativa [...]" (NEGO..., 1989). Isso, em certa medida, pode notar uma expectativa essencializada em torno da figura do maldito e um espaço de experiência a priori associado ao cenário independente ou alternativo da música brasileira, o que parece refletir em processos de estabilização da crítica por parte do maldito. Mais uma vez, destacamos como a análise de Sean Stroud, em 2010, aponta para a nova leitura em torno do trabalho de Itamar: 
Apesar da pequena escala desse primeiro lançamento, a reputação de Assumpção como um intérprete vibrante nas apresentações ao vivo indicava que ele estava construindo uma reputação para si, e seu primeiro LP recebeu críticas positivas unânimes na imprensa a tal ponto que, em 1981, ele foi saudado pela revista Veja como "um dos maiores talentos da música brasileira do momento" (SOUZA, 1981). A reação da imprensa a Assumpção foi estrondosamente laudatória, com jornalistas quase sempre se referindo a ele como um contraponto original à natureza medíocre e enfadonha da MPB contemporânea. É possível notar que muitos desses jornalistas (especialmente os que trabalhavam para os jornais de São Paulo) estavam ansiosos para dar seu apoio a um novo rumo dentro da música popular brasileira que tinha sua base em São Paulo, porque era uma tendência que poderia ser ligada à herança do experimentalismo de curta duração da tropicália. (STROUD, 2010, p. 90-91)

Nesse sentido, Itamar deixou o rol dos malditos? De acordo com a publicação do jornal, "[...] com o meio campo musical embolado por bandas xerox e arremedos beirando ao grotesco, Itamar permanecia imune ao ranço do tempo [...]", mas "[...] até quando na marginalidade? Resposta: 'Sampa Midnight - Isso Não Vai Ficar Assim! (1983) [...]", álbum gravado e lançado pela RCA, e que "[...] introduziu Itamar no circuito mais comercial das rádios [...]" (NEGO..., 1989), além do último lançamento pela gravadora Continental, do LP Intercontinental! Quem diria! Era só o que faltava! (1989). Assim, podemos observar as disputas e ambiguidades do discurso da Folha, pois parece afirmar que ao se vincular a uma gravadora ou ter seus discos tocados nas rádios, Itamar Assumpção, dentro dessa formação discursiva, estaria fora do rol e não seria mais mal-dito, ao menos diante de uma articulação entre um passado que já se foi e um futuro que estar por vir. Entre eles, um presente cujas expectativas e experiências acerca do artista maldito parecem estabilizar a crítica e instabilizar seus discursos, quando a acepção de ser maldito, na lógica da crítica, parece frustrada pelos lançamentos de discos associados a grandes gravadores e que passam a tocar nas rádios.

Assim, é possível formular, em contraposição aos achados em investigação posterior (CALDEIRA, 2018), na qual se identificou que parte da crítica, em um determinado momento, valorizava artistas que conseguiam ter contrato com 
grandes gravadoras e vender disco, no caso de Itamar Assumpção, este fato se torna uma diminuição do seu caráter maldito, que vem associado a outros valores.

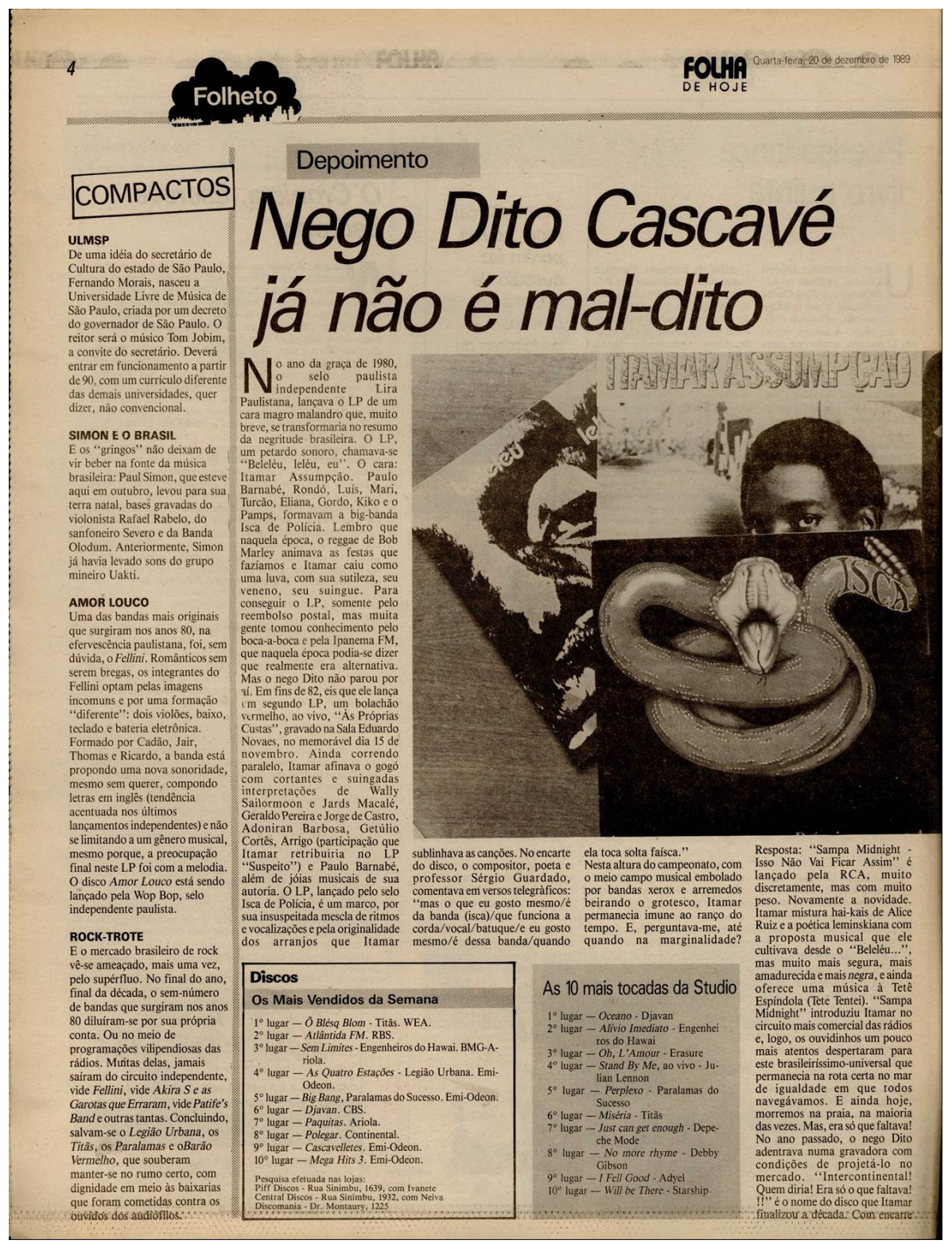

Figura 1: Nego Dito Cascavé já não é mal-dito

Fonte: Folha de S.Paulo (1989).

Nessa perspectiva, a publicação Bendito Itamar (2013), do site Vanguarda Paulista, afirma que o músico desde o seu primeiro disco Beleléu, Leléu e Eu (1980) estabelecia uma relação de enfrentamento com o esquema das majors: "[...] a sua opção pela independência artística e sua identificação com a marginalidade e com 
os temas ligados à periferia paulista renderam a Itamar o rótulo de 'maldito', título que ele renegava" (VANGUARDA PAULISTA, 2013). Aqui, podemos notar que as disputas valorativas estão permeadas entre o maldito e o bendito. De acordo com o Vanguarda Paulista (2013), Itamar Assumpção é bendito, principalmente, por ter estabelecido uma relação de enfrentamento com as grandes gravadoras, ou mesmo por "sua opção pela independência" e identificação com os circuitos marginais da música.

Nessa formação discursiva, se percebe um processo de estabilização que se dá pela negação do maldito e defesa do bendito, quando se afirma que a "[...] identificação com a marginalidade e com os temas ligados à periferia paulista renderam a Itamar o rótulo de 'maldito'[...]" ou "[...] que definir um artista tão complexo e completo quanto Itamar Assumpção não é uma tarefa fácil. [...]" (VANGUARDA PAULISTA, 2013). Ou seja, para negar o maldito também se faz necessário estabilizá-lo como bendito, configurando processos de estabilização em mão dupla, que tanto partem de uma formação discursiva de um bendito Itamar para negar o maldito Itamar, sendo ela operada pela crítica, como no sentido contrário, no qual o próprio termo, como uma atribuição considerada negativa, acaba também estabilizando a própria crítica, quando ela passa a negar o maldito em defesa do bendito e a formular discursos que ratifiquem essa negação:

Como bem disse a cantora Suzana Salles - que dividiu o palco com o músico inúmeras vezes - no documentário Daquele Instante em Diante (direção de Rogerio Velloso, 2011), que aborda a obra de Itamar: "O cara era uma complexidade só. Uma figura rara mesmo." Ou, como afirmou o compositor e musicólogo Luiz Tatit, líder do Grupo Rumo, no mesmo filme: "Ninguém fica ileso ao ouvir Itamar. A canção dele fere." De certo é que Itamar - juntamente com seus companheiros de Vanguarda mexeu com a música brasileira em um momento em que ela navegava em águas calmas [...]. "Daqui a cinquenta anos eu sou história ou não? Itamar Assumpção na história da música brasileira ou apenas mais um que passou?", perguntou Itamar, certa vez, em um depoimento. Precisa mesmo responder, Nego Dito?. (VANGUARDA PAULISTA, 2013) 
Conforme o trecho acima, podemos notar que para o site Vanguarda Paulista (2013), Itamar Assumpção é um bendito que foi "rotulado" como maldito. Entretanto, se tratando de disputas e relações de poder, devemos levar em consideração as experiências e as expectativas, as temporalidades e historicidades do termo maldito para evitar afirmações categóricas ou análises irrefutáveis. Assim, levando em conta os contextos, devemos nos atentar que a publicação é datada de 2013 (10 anos após a morte de Itamar, falecido em 2003), o que pode, em alguma medida, configurar outro espaço de experiências e horizonte de expectativas. Portanto, um outro espaço-temporal, principalmente em relação a formações discursivas de outras temporalidades.

A publicação do ano de 1995 Artistas têm fama de "difíceis e exigentes", do caderno Ilustrada da Folha de S. Paulo, parece reafirmar aquilo que nos anos 1970 e 1980 a crítica cultural e as grandes gravadoras em atuação no Brasil diziam sobre esses artistas: "eles são malditos porque são difíceis, quase impossíveis de lidar" (SANCHES, 1995). A construção da ideia de autenticidade em torno desses artistas, entendidos como difíceis de lidar porque "são autênticos, não se deixam guiar pelo que é dominante" (SANCHES, 1995), pode denotar um modo de disciplinar o aspecto político das produções desses artistas, com o intuito de manter uma ordem pré-formada na música brasileira. Um representante da indústria fonográfica afirma que "eles parecem cultivar o rótulo de 'malditos', talvez até por medo de voltar a gravar" (SANCHES, 1995) e que "os malditos são complicados, (pois) ainda têm a cabeça voltada para os anos 70" (SANCHES, 1995). Essas perspectivas atribuídas pela crítica cultural acerca do maldito expressam os enfrentamentos que ela estabelece com artistas avaliados positivamente por um grupo de ouvintes ou de fãs, mas que tiveram pouco acesso ao grande púbico e pouca visibilidade midiática.

Neste caso, o modo de ser maldito é uma referência direta, com uma construção discursiva de que os artistas são assim considerados por serem "[...] difíceis, quase impossíveis de lidar" ou porque "são autênticos, não se deixam guiar pelo que é dominante", o que faz deles "[...] complicados, (pois) ainda têm 
a cabeça voltada para os anos 70" (SANCHES, 1995). Novamente, a partir de sua historicidade, o maldito é colocado em posição de reprovação, como uma incapacidade de dialogar com o dominante, ou ao mesmo tempo Itamar só é maldito em relação ao dominante. Aqui, o discurso da crítica atua enquanto enfrentamento às produções, que ela considera "não consensuais" com suas expectativas e experiências, e postula uma defesa dos padrões dominantes relacionados ao mercado da música.

$\mathrm{Na}$ tentativa de construir contextos, podemos afirmar que o maldito, como uma figura de historicidade, traz em si uma série de enunciados e distintos modos de distribuição das sensibilidades, promovendo oscilações e ambiguidades discursivas. Como exemplo disso, a publicação $A$ gente nunca sabe o que, do site Tyrannus Melancholicus, datada de 9 de Julho de 2019, afirma que:

Rotular é com a imprensa e a academia gosta. Usa e abusa. Há necessidade de se rotular tudo, para compreender melhor a origem da criação e contextualizá-la, ou simplesmente porque facilita o que não é entendido. Itamar Assumpção, Jorge Mautner, Tom Zé, Arrigo Barnabé e Luiz Melodia, entre outros [...] São artistas de inegável qualidade, mas que nunca gozaram de um reconhecimento significativo e também não levantaram um dedinho sequer para facilitar nada. Quem estiver preparado que aprecie o biscoito fino: "diz-me com quem tu andas que eu te direi quem és". O mundo é assim: benditos prum lado, malditos pro outro... Entre eles, outros universos rotulavam. E as injustiças estão por toda a parte. Mas há a certeza de que muitos malditos, preferem, ou teriam preferido, o tal rótulo. (TYRANNUS MELANCHOLICUS, 2019)

No excerto acima, se tornam evidentes as oscilações discursivas e construções ambíguas acerca do maldito, ainda que, por um lado, se afirme que o ato de rotular seja algo simples, fácil e uma necessidade da imprensa "[...] para compreender melhor a origem da criação e contextualizá-la, ou simplesmente porque facilita o que não é entendido [...]", por outro, acaba por confirmar e reconhecer que exista os "[...] benditos prum lado, malditos pro outro... [e que] entre eles, [existem] outros universos [que] rotulavam [...]", considerando que "[...] as injustiças estão por toda a parte. Mas há a certeza de que muito malditos 
preferem, ou teriam preferido, o tal rótulo" (TYRANNUS, 2019). Além disso, parece que também há uma relação forte com o caráter experimental e distintivo de qualidade, pois a própria expressão "biscoito fino", de certa forma, remete a isso, tanto na expressão como na relação com a própria gravadora, que se coloca no mercado como distinta devido seu catálogo de artistas ditos de qualidade.

Nesse ponto, se torna evidente a necessidade destacada por Grossberg (1997) de não apenas identificar e analisar os textos e os discursos, mas ir além deles e pensar em formas intertextuais em que os contextos e os efeitos das práticas discursivas decorram de atravessamentos e transversalidades, que emerjam não de identidades essencializadas. Por isso, nos atentamos aos aparatos técnicos, tecnológicos, estéticos e políticos da crítica, enquanto um modus operandi que, de maneira transversal aos contextos, articula formações discursivas e sensibilidades não universalistas, mas que são disputadas. No caso específico do site Tyrannus Melancholicus (2019), essas disputas valorativas e de valores se dão na relação entre as formas dominantes e/ou hegemônicas da crítica e as contradições relacionadas aos aspectos culturais, sociais e políticos, que na construção de contextos parecem articuladas em relações de poder específicas.

Diante desses desdobramentos históricos e temporais que nos ajudam a pensar nos modos de se falar de contextos, chamamos atenção para questões potentes com relação à política e à estética no período da ditadura militar brasileira (1964-1985), e aos tensionamentos com o mercado de discos dos anos 70 e 80 . São eles os aspectos socioculturais e étnico-raciais presentes em Itamar Assumpção, observados como forma de entender o porquê alguns artistas da música brasileira foram chamados de malditos em formações discursivas da crítica. Pois, ao que parece, existem ao menos dois movimentos: se tem o maldito no sentido "ruim" e/ou "bom" diante de uma relação com as continuidades e descontinuidades discursivas na crítica, que demonstram reiterações ou rupturas valorativas com as produções de Itamar; e se tem os movimentos do próprio artista enquanto modos de disputar tais construções.

Compreendemos, desse modo, que existem algumas questões potentes para se pensar o rótulo de maldito em Itamar, quais sejam: na sua relação com 
a ditadura militar, quando contesta politicamente o regime a partir de performances musicais entendidas como "revolucionárias", e disputas no âmbito étnico-racial (o ato de se autointitular nego dito sem medo de polícia), como se pode notar na letra da música de mesmo nome, composta em 1980: "Se chamá polícia/Eu viro uma onça/ Eu quero matar/A boca espuma de ódio". Além disso, sua atuação como artista de uma vanguarda paulista, que trazia tais disputas até mesmo no nome de sua banda, "Itamar Assumpção e a Isca de polícia", pode demonstrar potencial contestador na relação não somente com o mercado e com a crítica no âmbito estético-musical, nas letras e construções de suas músicas ao fazer uso do experimentalismo, atonalismo ${ }^{13}$ sonoro e outros recursos artísticos, como também trazendo discursos relacionados às questões sociais, de raça, cor e política no espaço-temporal de repressão e censura da ditadura militar no Brasil.

Entretanto, outros artistas do mesmo período, como os tropicalistas, não foram considerados malditos ao performar e propor outras formas estéticas, ou mesmo ao contestar a ditadura, não lhes coube a alcunha de malditos. Logo, ao que parece, a questão do maldito tem a ver com as "inovações" no âmbito da estética musical e das sensibilidades e de distribuição sensível, mas também com a contraposição às lógicas do mercado, das cenas musicais hegemônicas na relação com o popular, com a cultura pop, com o universo da canção naquela época, o que confronta, até certo ponto, o censor da crítica e suas regulações. Ainda que com a ciência de que os tropicalistas também propuseram "inovações" em um sentido semelhante, ressaltamos que eles, de alguma forma, se mantiveram em diálogo com as lógicas de produção e recepção do mercado das majors na época, compondo uma tessitura espaço-temporal em associação ao hegemônico, seja na crítica ou na música nacional.

Destacamos também que outros artistas considerados "inovadores", experimentais ou de vanguarda na relação com o hegemônico, como o compositor a grande maioria das músicas e canções, e portanto não tem uma tonalidade preponderante. É um tipo de música que não se conforma diante de um sistema de hierarquias. Podemos dizer que as notas de uma escala (cromática ou não) trabalham em independência perante à nota principal de uma escala musical (conjunto de notas em sequência). 
paraibano Fernando Falcão (1945-2002), não foram considerados malditos por suas performances e estéticas compreendidas com "inovadoras", nem pelo seu envolvimento com as questões políticas no Brasil ditatorial. Desde a juventude, Fernando Falcão se envolveu com os movimentos estudantis contra a ditadura até se exilar em 1969, ano seguinte à promulgação do AI- $5^{14}$, em Paris, onde viveu por 12 anos. Ao contrário disso, de acordo com publicação do site Nexo (2019), intitulada "Obscuro músico que influenciou Alceu Valença e Fagner", o artista "[...] se junta a outros brasileiros esquecidos no país e apreciados pelo público estrangeiro" (ROCHA, 2019), tendo seu disco Memórias das águas (1979) relançado em 2019, além de álbuns póstumos lançados por gravadoras estrangeiras, como a coletânea Outro tempo (2017), que reúne músicos considerados "esquecidos ou obscuros", como May East, Akira S e Fausto Fawcet, lançada pela Music From Memory (Holanda), e o disco Engenho de meninos (2002), lançado após sua morte.

Diante disso, queremos chamar atenção para a construção de um contexto no qual o termo maldito não é geral nem generalista para designar todo e qualquer artista que transita pelas cenas alternativas ou independentes ao hegemônico. Pensando dessa forma, parece evidente que a própria noção do que é essa articulação ou disputa entre hegemônico e não hegemônico envolve processos mais complexos, dos quais talvez não daremos conta neste artigo, mas para os quais chamaremos a atenção. Como é o caso de Fernando Falcão numa comparação com Itamar Assumpção, o primeiro entendido como "esquecido" ou "obscuro" e o segundo reconhecido como "maldito", "de vanguarda" e "alternativo" perante à crítica. Isso traz à tona as complexidades desses processos, pois envolvem até mesmo uma relação de ordem regional - um nascido na Paraíba (Nordeste), outro nascido no estado de São Paulo (Sudeste), região considerada o centro da cultura do país, onde tudo acontece. Tal perspectiva, de certa forma, nos faz pensar que Itamar aconteceu ao menos em alguns nichos da cultura, não necessariamente flertando com o dominante, mas ainda se articulando, de alguma maneira, entre 
a crítica, o mercado etc. Ou seja, ele estava e está em algum lugar do imaginário musical brasileiro.

Dessa forma, ainda que para o mercado das majors, ser maldito era estar fora dele ou não se enquadrar nele, podemos dizer que isso não é algo estanque, pois partindo de horizontes de expectativas e espaços de experiências e pensando no maldito como figura de historicidade, se percebe que o termo foi ora entendido com algo "bom" na relação com as vanguardas e nichos culturais, ora como "ruim" na relação com os regimes de verdade dos séculos XIX e XX. Ou seja, notamos ambiguidades nos discursos dos críticos, colocando esses artistas como "diferentes" ao dominante ou "geniais" no cenário musical alternativo ou independente. Todavia, isso não finda o maldito em si e nem na trajetória de Itamar, ao contrário, se nota que as institucionalidades e as práticas culturais de um tempo ajudam a entender as recorrentes oscilações nos tempos históricos.

Ressaltamos que essas disputas valorativas e de valores acerca do maldito não se restringem aos críticos, já que se pode observá-las entre outros artistas, fãs, amigos e parentes e nos próprios discursos de Itamar. Na publicação Itamar Assumpção: Maldito, não. Revolucionário, do site de Bruno Hoffmann, destaca-se que o músico paulista demonstrava aversão à fama de artista marginal ou artista maldito, e que costumava dizer: "a música é meu patrimônio e eu mando na minha carreira. Maldito, não. Sou um revolucionário" (HOFFMANN, 2014). Observando as variadas instâncias que envolve o mercado de discos, a trajetória artística e as práticas políticas de Itamar, como as relacionadas às questões de raça e cor e as disputas com o mercado fonográfico brasileiro, além das construções discursivas do artista e da crítica, se ratifica que o maldito na música brasileira não é algo estrito ou delineado, conformado ou homogêneo, mas envolve processos contínuos e descontínuos em torno de disputas, valores e discursos variados e distintos.

O próprio Itamar costumava questionar essa construção: "as pessoas não entendem e afirmam que sou maldito. O fato de eu não me entregar às abobrinhas musicais resulta em uma série de rótulos equivocados sobre mim" (HOFFMANN, 2014). Desse modo, se torna evidente que existe um jogo de 
relações de poder, que articulam o mercado fonográfico dominante, a crítica cultural hegemônica e os espaços alternativos como processos de disputas que deixam ver apropriações e desapropriações discursivas diante das institucionalidades da crítica cultural, o que também envolve expectativas e experiências várias em torno da trajetória do músico.

\section{Algumas considerações sobre a multiplicidade do "maldito"}

Diante do fenômeno apresentado ao longo do texto, compreende-se que é possível perceber o contexto presente também como "em disputa", e não garantia de mudanças imediatas na trajetória de Itamar Assumpção e sua rotulação como "maldito". Essa articulação é uma possibilidade de construir ou desconstruir algo diferente no presente, no futuro e no passado. Observamos, aqui, alguns desses deslocamentos ao longo das leituras e interpretações feitas pela crítica hegemônica sobre a obra de Itamar Assumpção.

De alguma forma, ratificamos que as lógicas do mercado de discos e da crítica cultural no contexto brasileiro atuam de maneira censória ou regulatória, ao mesmo tempo que contemplam nuances e misturas consideradas aceitáveis diante das ambiguidades e complexidades. A partir da análise das disputas valorativas e de valores, das experiências e expectativas em torno da trajetória de Itamar, demonstramos que artistas considerados experimentais, com produções musicais de difícil classificação, são enquadrados no rótulo "maldito". Contudo, percebe-se que não somente aspectos formais definem essa rotulação, uma vez que há artistas "inovadores" e/ou "experimentais" que não receberam tal alcunha, dentre eles, os tropicalistas e Fernando Falcão. Dessa forma, entendemos que as disputas em torno do termo envolvem sua densidade histórica e sua espaçotemporalidade, por isso ele não é geral ou generalista, estanque ou findado em si mesmo. Daí a análise de Ferraz (2013, p. 7) de que "poucos fracassos, na história da música popular brasileira, parecem ter sido tão bem-sucedidos quanto o de Itamar Assumpção".

Diante disso, entendemos que se Itamar Assumpção é, em algumas formações da crítica, considerado complicado, isso tem a ver não somente com 
as experimentações sonoras que são colocadas como difíceis de serem aceitas pelo público, mas também por uma adequação precária às lógicas da indústria musical e pelo diálogo tensivo com as temporalidades e historicidades consolidadas na época. Há um desarranjo articulado com as lógicas de produção e recepção, com os regimes de verdades a partir dos quais a atividade da crítica cultural se amparava. Essa relação do tempo, expectativas e experiências com as produções em geral e as de Itamar, em particular, apresentam um caminho possível de análise para refletir sobre como as formas de distinção do termo "maldito", na relação com a carreira de Itamar (um artista que negava o maldito pela via do independente), contribuem para uma reflexão sobre o popular, o dominante e o alternativo e/ou independente na cultura brasileira.

\section{Referências}

"ARTISTAS malditos não existem mais", diz curados de colóquio da USP sobre o tema. Folha de S.Paulo, São Paulo, 22 maio 2013. Disponível em: https://www1. folha.uol.com.br/ilustrada/2013/05/1282406-artistas-malditos-nao-existem-maisdiz-curador-de-coloquio-da-usp-sobre-o-tema.shtml. Acesso em: 20 jun. 2019.

ASSUMPÇÃO, I. Antônio Abujamra entrevista Itamar Assumpção. [Entrevista cedida a Antônio Abujamra]. Programa Provocações, TV Cultura, São Paulo, 2001. Disponível em: https://www.youtube.com/watch?v=TC_2dOZE2Kc. Acesso em: 10 set. 2018.

CALDEIRA, L. Estudando Tom Zé: crítica musical e o estético-político. 2018. Dissertação (Mestrado em Comunicação e Cultura Contemporânea) - Faculdade de Comunicação, Universidade Federal da Bahia, Salvador, 2018.

CALDEIRA, L.; FARIAS, D. Disputas valorativas de críticos e fãs a partir das trajetórias de Jards Macalé e Elza Soares. In: ENECULT - ENCONTRO MULTIDISCIPLINARES 
EM CULTURA, 15., 2019, Salvador. Anais [...]. Salvador: Ufba, 2019. Disponível em: http://www.enecult.ufba.br/modulos/submissao/Upload-484/111802.pdf. Acesso em: 15 ago. 2019.

CARDOSO FILHO, J.; JANOTTI JÚNIOR, J. A música popular massiva, o mainstream e o underground: trajetórias e caminhos da música na cultura midiática. In: CONGRESSO BRASILEIRO DE CIÊNCIAS DA COMUNICAÇÃO, 29., 2006, Brasília, DF. Anais [...]. Brasília, DF: Intercom, 2006.

GROSSBERG, L. Cultural studies in the future tense. Durhan: Duke University Press, 2010.

GROSSBERG, L. Dancing in Spite of Myself. Duke University Press, 1997.

GROSSBERG, L. Lutando com anjos: os estudos culturais em tempos sombrios. MATRIZes, São Paulo, v. 9, p. 13-46, 2015.

FERRAZ, I. Música como missão: experiência e expressão em Itamar Assumpção. 2013. Dissertação (Mestrado em Filosofia) - Escola de Filosofia, Letras e Ciências Humanas, Universidade Federal de São Paulo, Guarulhos, 2013.

FOUCAULT, M. A ordem do discurso. São Paulo: Loyola, 2014.

FOUCAULT, M. A arqueologia do saber. Rio de Janeiro: Forense, 1987.

FOUCAULT, M. A arqueologia do saber. Tradução de Luiz Felipe Baeta Neves, 7. ed. Rio de Janeiro: Forense Universitária, 2008.

HARTOG, F. Regimes de historicidade: presentismo e experiências do tempo. Belo Horizonte: Autêntica, 2019. 
HOFFMANN, B. Itamar Assumpção: maldito, não. Revolucionário. Bruno Hoffmann, Brasil, 2014. Disponível em: https://brunohoffmann.wordpress.com/2014/08/05/ maldito-nao-revolucionario/. Acesso em: 7 maio 2019.

KALIK, A. Benedito João dos Santos Siva Beleléu, Vulgo Nego Dito, maldito bendito, Itamar. Çaravá, Brasil, 2017. Disponível em: https://caravaculture.wordpress. com/2015/09/02/benedito-joao-dos-santos-siva-beleleu-vulgo-nego-dito-malditobendito-itamar/. Acesso em: 27 jun. 2019.

KOSELLECK, R. Futuro passado: contribuição à semântica dos tempos históricos. Rio de Janeiro: Contraponto, 2006.

Nego Dito Cascavé já não é mal-dito. Folha de S.Paulo, São Paulo, 20 dez. 1989.

RIBEIRO, A. P. G.; LEAL, B. S.; GOMES, I. M. M. A historicidade dos processos comunicacionais: elementos para uma abordagem. In: MUSSE, C. F. ; VARGAS, H. ; NICOLAU, M. (ed.). Comunicação, mídias e temporalidades. Salvador: Edufba, 2017. p. 37-58.

ROCHA, C. O obscuro músico que influenciou Alceu Valença e Fagner. Jornal Nexo, São Paulo, 2019. Disponível em: https://www.nexojornal.com.br/expresso/2019/08/21/ O-obscuro-m\%C3\%Basico-que-influenciou-Alceu-Valen\%C3\%A7a-e-Fagner. Acesso em: 20 ago. 2019.

SANCHES, P. A. Artistas têm fama de "difíceis e exigentes". Folha de S.Paulo, São Paulo, 25 abr. 1995. Disponível em: https://www1.folha.uol.com.br/ fsp/1995/4/25/ilustrada/7.html. Acesso em: 13 set. 2018.

STROUD, S. Música popular brasileira experimental: Itamar Assumpção, a vanguarda paulista e a tropicália. Revista USP, São Paulo, n. 87, p. 86-97, 2010. 
TYRANNUS MELANCHOLICUS. A gente nunca sabe o que. Tyrannus Melancholicus, Cuiabá, 2019. Disponível em: http://www.tyrannusmelancholicus.com.br/ cronicas/1274/a-gente-nunca-sabe-o-que. Acesso em: 15 jul. 2019.

VANGUARDA PAULISTA. Bendito Itamar!. Vanguarda Paulista, São Paulo, 2013. Disponível em: http://www.vanguardapaulista.com.br/bendito-itamar/. Acesso em: 7 maio 2019.

VIVAS, F. Os poetas malditos e sua influência no século XX. Esquerda Diário, [s. l.], 24 mar. 2015. Disponível em: https://www.esquerdadiario.com.br/Ospoetas-malditos-e-sua-influencia-no-seculo-XX. Acesso em: 27 jun. 2019.

WILLIAMS, R. Marxismo e literatura. Tradução de Waltensir Dutra. Rio de Janeiro: Zahar, 1979.

submetido em: 30 jul. 2020 | aprovado em: 23 dez. 2020 